\title{
Epithelioid Hemangioendothelioma of Mandible: A Rare Case Report with Immunohistochemical Studies
}

\author{
${ }^{1}$ Deepak Verma, ${ }^{2}$ Shalini Varshney, ${ }^{3}$ Mohamed Shareef, ${ }^{4}$ Shweta Gupta, ${ }^{5}$ Megha Verma
}

\begin{abstract}
We report here a rare case of epithelioid hemangioendothelioma (EHE) of mandible in an adult male, who presented to our department with a huge mass protruding out of the oral cavity. The patient underwent wide local excision of the mass, and histopathological features favored the diagnosis of EHE, which was finally confirmed by immunohistochemistry with CD31 tumor marker.
\end{abstract}

Keywords: Epithelioid hemangioendothelioma, Immunohistochemistry, Vascular tumor.

How to cite this article: Verma D, Varshney S, Shareef M, Gupta S, Verma M. Epithelioid Hemangioendothelioma of Mandible: A Rare Case Report with Immunohistochemical Studies. Int J Oral Implantol Clin Res 2016;7(1):7-9.

\section{Source of support: Nil}

Conflict of interest: None

\section{INTRODUCTION}

Vascular tumors can be divided into two different types. The first type is characterized by the formation of new blood vessels or cavernous spaces and includes benign hemangioma and its malignant counterpart, hemangiosarcoma. The second type of vascular tumors is formed from predominant cell types found in the adventitia, media, and intima of blood vessel walls, e.g., hemangiopericytoma, leiomyoma, leiomyosarcoma, and hemangioendothelio$\mathrm{ma}^{1}$. Epithelioid hemangioendothelioma (EHE) is an angiocentric vascular tumor with metastatic potential. Although previously known as angioglomoid tumor, histiocytoid hemangioma, or myxoid angioblastomatosis, the term EHE was originally given by Weiss and Enzinger. ${ }^{2-4}$ This tumor was described by the World Health Organization (WHO) as a vascular tumor with intermediate biological properties

\footnotetext{
${ }^{1-4}$ Senior Resident, ${ }^{5}$ Resident

${ }^{1}$ Department of ENT and HNS, BPS Government Medical College for Women, Sonepat, Haryana, India

${ }^{2-4}$ Department of ENT and HNS, Vardhman Mahavir Medical College and Safdarjung Hospital, New Delhi, India

${ }^{5}$ Department of Dental Surgery, BPS Government Medical College for Women, Sonepat, Haryana, India

Corresponding Author: Deepak Verma, Senior Resident Department of ENT and HNS, BPS Government Medical College for Women, Sonepat, Haryana, India, Phone: +918689037330 e-mail: dpkvrm20@gmail.com
}

between hemangioma and angiosarcoma. ${ }^{5}$ Histologically, tumor consists of epithelioid endothelial cells arranged in short cords and nests with fibromyxoid stroma. Clinically, the tumor can occur in nearly all age groups, ranging from the first to the seventh decade. Men and women are equally affected by this tumor. ${ }^{6}$ It can arise in soft tissues, viscera, skin, and bone. ${ }^{7,8} \mathrm{~A}$ few cases have been reported in the head and neck region including neck, thyroid gland, larynx, and scalp. ${ }^{9-11}$ This tumor is extremely rare in the oral cavity, with the gingival alveolar mucosa and tongue being reported as the most common intraoral sites. ${ }^{6}$

\section{CASE REPORT}

A 25-year-old man presented with a 5-month history of a slowly growing painless mass protruding out of the oral cavity, causing difficulty and pain during swallowing. The patient's medical history was nonsignificant. The external examination revealed an oval-shaped mass protruding out of the oral cavity and appeared to involve the mandible (Fig. 1). The mass was nontender, but bled on touch, and there was no associated lymphadenopathy. Contrast-enhanced computerized tomography scan showed large soft tissue density mass lesion with heterogeneous enhancement arising from the left side of the mandible, with few calcific foci within causing erosion of the underlying mandibular cortex (Fig. 2). Wide local excision of the mass with safety margins was done and the specimen was sent for histopathological examination. Grossly, the tumor was firm and rubbery with a grayish-tan cut surface along with hemorrhagic foci. Histologically, the hematoxylin and eosin-stained specimen exhibited cords and a solid nest growth pattern within a collagenous and myxoid

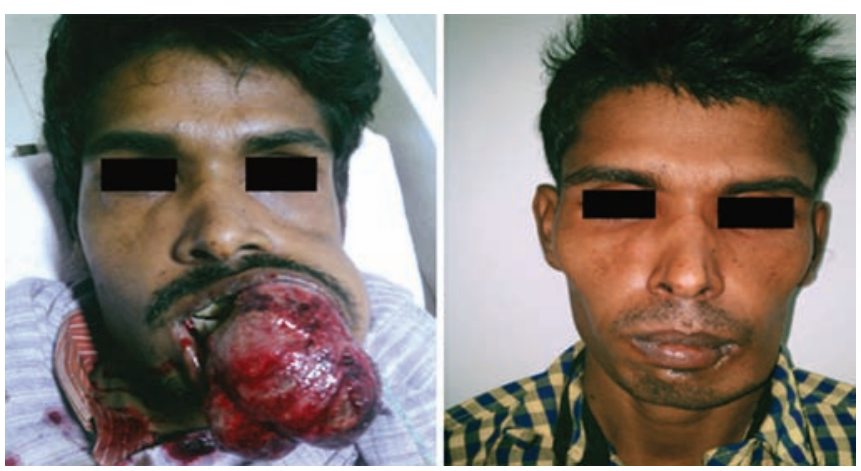

Fig. 1: Preoperative and postoperative picture of patient 


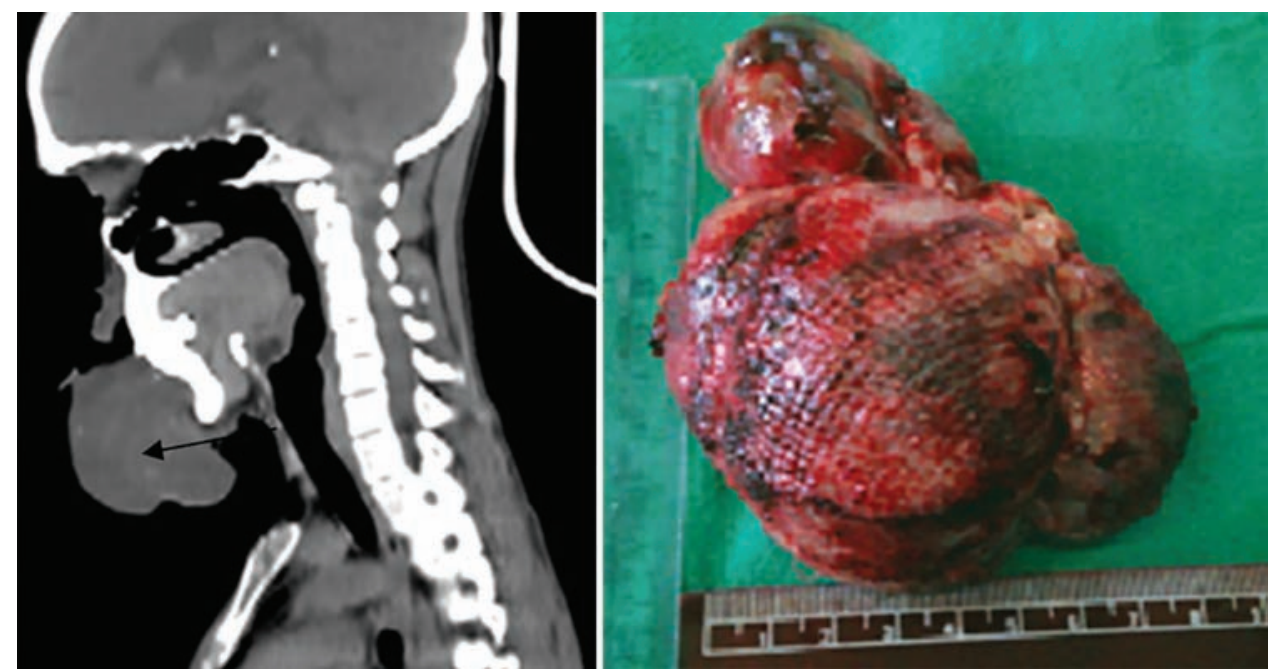

Fig. 2: Computerized tomography scan picture and gross appearance of tumor
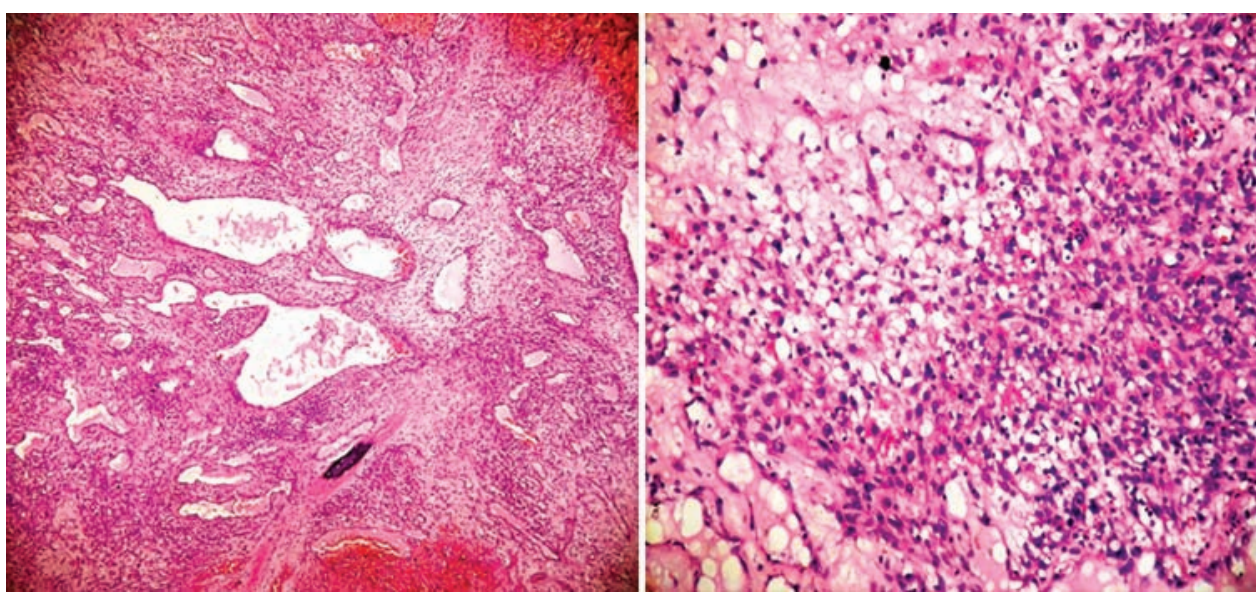

Fig. 3: Histopathological picture of the tumor

noninflammatory stroma (Fig. 3). The tumor cells were epithelioid, rounded, or slightly spindled in shape, with an esinophilic cytoplasm. Scattered vascular channels containing erythrocytes were also seen, whereas mitotic figures were sparsely found. All these findings were in favor of EHE. Immunohistochemistry with CD31 tumor marker was performed for final confirmation, and the tumor was found strongly positive for this marker. Patient was under regular follow-up for 1 year and is now doing fine without any recurrence.

\section{DISCUSSION}

The EHE is a vascular tumor i.e., included in a group of neoplasms named as histiocytoid hemangioma by Rosai et al, which is thought to be derived from specialized cells called epithelioid endothelial cells that on proliferation form vascular mass with occasional propensity of locally aggressive nature, large vascular invasion, and lymph node metastasis. Many authors have found its clinical course intermediate between hemangioma and angiosarcoma, but it is differentiated from ordinary hemangioma by the absence of large vascular channels. Due to the rarity of this tumor and distinctive histopathological picture, it has often been misdiagnosed as carcinoma. Various differential diagnoses should be kept in mind including epithelioid angiosarcoma, spindle cell hemangioma, kaposiform hemangioendothelioma, and epithelioid angiomatous nodule. Epithelioid angiosarcoma is an infiltrative vascular tumor composed of pleomorphic cells with atypical mitosis and frequently with necrosis. ${ }^{12}$ In contrast, EHE does not show the degree of pleomorphism or atypical mitosis classically seen in epithelioid angiosarcoma. However, the diagnosis can be confirmed by histochemical studies with factor VIII-related antigen and CD31 marker, which was done in our case and found to be strongly positive.

Wide local excision with safety margins is considered the treatment of choice for this tumor. ${ }^{13}$ The role of adjuvant chemotherapy, radiotherapy, and/or treatment with interferon, although explained in the literature, remains unclear till date. Radiotherapy alone is not very effective because of the slow growth of the tumor cells. 
Depending on the organ affected, mortality from the tumor varied greatly $-13 \%$ in soft tissue ${ }^{8}$ and $35 \%$ in the liver. ${ }^{7}$ Metastasis has been seen in approximately $20 \%$ of patients with soft tissue primary and $25 \%$ with liver primary. According to the literature, behavior of intraoral EHE appeared less aggressive than that arising from the soft tissues and bones. Late recurrence has been reported for this tumor in the literature; therefore, a long follow-up is recommended.

\section{CONCLUSION}

Epithelioid hemangioendothelioma is a rare vascular tumor with metastatic potential and having intermediate biological properties between hemangioma and angiosarcoma. This should be kept as a differential diagnosis in any patient presenting with similar swelling, and a prompt management protocol should include radiological investigations followed by wide local excision with safety margins. Due to the known propensity of late recurrence, long follow-up is recommended for such types of tumors.

\section{REFERENCES}

1. Phillips H, Brown A, Ball M. Hemangioendothelioma: report of a case. J Oral Surg 1969 Apr;27(4):286-288.

2. Weiss SW, Enzinger FM. Epithelioid hemangioendothelioma: a vascular tumor often mistaken for a carcinoma. Cancer 1982 Sep;50(5):970-981.

3. Weiss SW, Ishak KG, Dail DH, Sweet DE, Enzinger FM. Epithelioid hemangioendothelioma and related lesions. Semin Diagn Pathol 1986 Nov;3(4):259-287.

4. Rosai J, Gold J, Landy R. The histiocytoid hemangiomas: a unifying concept embracing several previously described entities of skin, soft tissue, large vessels, bone, and heart. Hum Pathol 1979 Nov;10(6):707-730.

5. Angervall L, Kindblom LG, Karlsson K, Stener B. Atypical hemangioendothelioma of venous origin. A clinicopathologic, angiographic, immunohistochemical, and ultrastructural study of two endothelial tumors within the concept of histiocytoid hemangioma. Am J Surg Pathol 1985 Jul;9(7):504-516.

6. Chi AC, Weathers DR, Folpe AL, Dunlap DT, Rasenberger K, Neville BW. Epithelioid hemangioendothelioma of the oral cavity: report of two cases and review of the literature. Oral Surg Oral Med Oral Pathol Oral Radiol Endod 2005 Dec;100(6): 717-724.

7. Makhlouf HR, Ishak KG, Goodman ZD. Epithelioid hemangioendothelioma of the liver. Cancer 1999 Feb;85(3): 562-582.

8. Mentzel T, Beham A, Calonje E, Katenkamp D, Fletcher CD. Epithelioid hemangioendothelioma of skin and soft tissues: clinicopathologic and immunohistochemical study of 30 cases. Am J Surg Pathol 1997 Apr;21(4):363-374.

9. Siddiqui MT, Evans HL, Ro JY, Ayala AG. Epithelioid hemangioendothelioma of the thyroid gland: a case report and review of literature. Histopathology 1998 May;32(5): 473-476.

10. Pigadas N, Mohamid W, McDermott P. Epithelioid hemangioendothelioma of the parotid gland. Oral Surg Oral Med Oral Pathol Oral Radiol Endod 2000 Jun;89(6): 730-738.

11. Amin KS, McGuff HS, Cashman SW, Otto RA. Epithelioid hemangioendothelioma of the parotid gland with atypical features. Otolaryngol Head Neck Surg 2003 Nov;129(5):596-598.

12. Triantafillidou K, Lazaridis N, Zaramboukas T. Epithelioid angiosarcoma of the maxillary sinus and the maxilla: a case report and review of the literature. Oral Surg Oral Med Oral Pathol Oral Radiol Endod 2002 Sep;94(3): 333-337.

13. Ellis GL, Kratochvil FJ 3rd. Epithelioid hemangioendothelioma of the head and neck: a clinicopathologic report of twelve cases. Oral Surg Oral Med Oral Pathol 1986 Jan;61(1): 61-68. 